\title{
Thwarted enthusiasm: effects of workplace incivility on newcomer proactive behaviors
}

Yuanyuan Lan, Yuhuan Xia, Shuang Li and Wen Wu

School of Economics and Management, Beijing Jiaotong University, Beijing, China

\author{
Jiaqi Hui \\ School of Management, University of St Andrews, St Andrews, UK, and \\ Hui Deng \\ School of Economics and Management, Beijing Jiaotong University, Beijing, China \\ Schin
}

\begin{abstract}
Purpose - The purpose of this study is to explore the relationship between supervisor and coworkers' workplace incivility and newcomer proactive behaviors. Drawing on conservation of resources (COR) theory, the authors examined resource depletion as a mediator and newcomer proactive personality, as well as their current organizational tenure as moderators of the relationship between workplace incivility toward newcomers and their proactive behaviors.

Design/methodology/approach - A time-lagged research design was used to test hypotheses with data covering 322 newcomers and their immediate supervisors in two subsidiaries of a large food processing company in China. Regression analysis using the PROCESS macro in SPSS is used to test the hypotheses.

Findings - The results show that workplace incivility toward newcomers is negatively related to their proactive behaviors. This relationship is mediated by resource depletion. Furthermore, newcomers' proactive personality moderates the relationship between workplace incivility and resource depletion. Moreover, both the direct effect of workplace incivility on resource depletion and its indirect effect on newcomer proactive behaviors are moderated by the combination of newcomer proactive personality and their current organizational tenure.

Originality/value - Drawing on COR theory, a theoretical framework is constructed that specifies the process through which workplace incivility affects proactive behaviors to expand collective understandings of workplace incivility in the newcomer context. Furthermore, the boundary conditions of the underlying process are investigated, which further enhances the contribution of this paper to the extant literature on workplace incivility.
\end{abstract}

Keywords Proactive behavior, Proactive personality, Workplace incivility, Newcomer, Resource depletion, Current organizational tenure

Paper type Research paper

(C) Yuanyuan Lan, Yuhuan Xia, Shuang Li, Wen Wu, Jiaqi Hui and Hui Deng. Published by Emerald Group Publishing Limited. This article is published under the Creative Commons Attribution (CC BY 4.0) licence. Anyone may reproduce, distribute, translate and create derivative works of this article (for both commercial and non-commercial purposes), subject to full attribution to the original publication and authors. The full terms of this licence may be seen at http://creativecommons.org/ licences/by/4.0/legalcode

The paper was supported by "the Fundamental Research Funds for the Central Universities" (2018JBWZB003; 2018YJS060).

Received 9 May 2019 Revised 14 November 2019 28 January 2020 5 April 2020 Accepted 17 April 2020 
CMS

14,4

\section{Introduction}

Workplace incivility, defined as "low-intensity deviant behavior with ambiguous intent to harm the target, in violation of workplace norms of mutual respect" (Andersson and Pearson, 1999), is prevalent in the modern world (Cortina and Magley, 2009; Lim and Lee, 2011). Note that 98\% of workers have experienced incivility, $\sim 50 \%$ of workers have to tolerate incivility every week, and $>67 \%$ of employees have experienced incivility from their supervisors (Spence Laschinger $e t a l$., 2009; Porath and Pearson, 2013). Research suggests that workplace incivility is harmful in terms of employees' increased psychological stress (Lim and Cortina, 2005), reduced job performance (Rahim and Cosby, 2016), decreased management effectiveness and increased costs (Porath and Pearson, 2013). Given these results, significant research effort has been devoted to further understanding the nature and impact of workplace incivility. Studies concerning workplace incivility can generally be distinguished based on two perspectives. Some researchers argue that workplace incivility is negatively related to employees' mental and physical health (Lim et al., 2008; Hershcovis et al., 2017). Others have sought to determine the relationship between workplace incivility and employees' behaviors (Rahim and Cosby, 2016; Fida et al., 2018) or employees' feelings (Lim et al., 2008; Abubakar, 2018).

Despite this progress in workplace incivility studies, numerous questions still require further exploration. First, there is a dearth of research into the impact of incivility on newcomers (Ellis et al., 2017). Compared with seasoned employees, newcomers are more likely to become targets of workplace incivility (Pearson et al., 2000) because of their unique characteristics (e.g. lower organizational status, greater tension and stress, likelihood of feeling nervous and insecure). Second, recent incivility studies have focused on psychological perception and in-role behavior (Sliter et al., 2012; Giumetti et al., 2013), but very less attention has been devoted to the target's proactive behaviors (Bateman and Crant, 1993). When an individual occupies a new position in an organization, he/she may engage in proactive behaviors to improve her/his organizational socialization and career success (Gruman et al., 2006). However, it is unclear whether newcomers still positively engage in those behaviors when experiencing workplace incivility. Moreover, newcomers are heterogenous in terms of their personal characteristics. Nevertheless, previous studies have not sufficiently explained the role of personal characteristics on the relationship between current organizational tenure and its potential consequences. Furthermore, the current organizational tenure affects employees' ability to deal with difficult situations in the workplace. It is unclear whether the effects of workplace incivility on proactive behaviors vary across newcomers with different current organizational tenure.

This paper used the conservation of resources (COR) theory (Hobfoll, 1989) to understand the impact of workplace incivility on newcomer proactive behaviors. According to the COR theory, negative work-related experiences that give rise to psychological stress can threaten or cause resource depletion (Grandey and Cropanzano, 1999; De Cuyper et al., 2012). Consequently, individuals who lack resources are predicted to guard the resources which they do possess (Hobfoll and Lilly, 1993), rather than investing resources to subsequent tasks. Furthermore, the influence of workplace incivility on newcomers could considerably differ among individuals because of personal characteristics. Individuals with proactive personalities tend to change their surroundings intentionally (Bakker et al., 2012) to avoid being the target of workplace incivility or to minimize its negative influence. Beyond personal characteristics, the current organizational tenure of newcomers may impact the extent to which they become targets for workplace incivility. For example, it is reasonable to posit that brand new employees (i.e. employees who have worked for the current organization for 3 months or less) may differ from late-stage new employees (i.e. employees 
who have worked for the current organization between 4 and 6 months) in this context. One reason why current organizational tenure length could be important here is related to the ability to handle stress in the workplace. Considering how a proactive personality and current organizational tenure simultaneously affect the situation can be more complex. Herein, responding to a call by Schilpzand et al. (2016), newcomers' proactive personality and current organizational tenure are operationalized as moderators to understand the relationship between workplace incivility toward newcomers and their proactive behaviors.

This study makes three contributions to the literature. First, the paper contributes to research on newcomers by discussing the detrimental impact of workplace incivility on this group of employees. This is important because newcomers are the "fresh blood" of an organization. Newcomers' first impressions of the organization determine their opinions concerning whether they should continue to work there. In this respect, it is important to note that turnover actually occurs more among newcomers. Because workplace incivility is negative and leads to numerous deleterious consequences, understanding incivility in the context of newcomers is of great importance. Second, this study advances the workplace incivility literature by demonstrating whether, how and under what conditions workplace incivility affects newcomers' proactive behaviors. In doing so, the current study enriches the nomological network of workplace incivility by scrutinizing its downstream effects on proactive behaviors. Third, this study investigates the boundary conditions of the influence of workplace incivility on proactive behaviors in the newcomer context. Specially, employees' current organizational tenure is an important indicator of whether they are vulnerable to workplace incivility. By integrating proactive personality and current organizational tenure, an attempt is made to gain a better understanding of the conditions and processes that attenuate or strengthen the effects of workplace incivility toward newcomers.

\section{Theory and hypotheses}

Conservation of resources theory

COR theory serves as the overarching theoretical framework for this study pursuant to explaining the causes and possible consequences of psychological stress (Hobfoll and Shirom, 2001). According to COR theory, resources are defined as valuable things or means to achieve a goal; they include internal and external resources such as objective resources, conditions, personal characteristics and energy resources (Hobfoll, 1989). Although resources refer to anything that is beneficial to individuals, to be consistent with extant studies (Halbesleben and Bowler, 2007), this paper defines resources as subjective psychological energy that is affected by environmental factors such as stress (Ten Brummelhuis and Bakker, 2012).

The principal tenet of COR theory is that individuals are trying their best to obtain, retain, protect and foster what they value (Hobfoll, 2001). Because resource loss weighs more than resource gain, when an individual is under the pressure of resource depletion, they will tend to minimize losses and protect against further loss by decreasing their resource investment (Hobfoll, 1989; Hobfoll and Freedy, 1993). COR theory posits that work-related stress can predict resource depletion; however, individual differences can be treated as resources and can affect how people react to stress (or resource loss). For example, some individuals may be more skilled at minimizing their losses (Grandey and Cropanzano, 1999). Thus, COR theory is particularly relevant to this research because it provides a useful framework to understand how newcomers' behaviors may change under pressure. 
CMS

14,4

1038

Figure 1.

The theoretical framework of this research

\section{Understanding workplace incivility and conservation of resources theory}

It is necessary to explain and define workplace incivility in detail. First, incivility has three notable characteristics: low intensity, vague intentions toward the target and violation of mutual respect norms (Andersson and Pearson, 1999). Examples of uncivil conduct include using demeaning language and condescending tone, disparaging their reputation and ignoring their requirements (Porath and Pearson, 2012; Lim et al., 2016). Second, workplace incivility involves targets and perpetrators. Individuals with lower social power in organizations, such as newcomers, gender minorities and younger people, are more vulnerable to incivility (Cortina et al., 2001; Vecchio, 2005). Third, workplace incivility is not only a type of workplace stress (Penney and Spector, 2005) but also a type of interpersonal conflict (Sliter et al., 2012). It can disturb sleep (Yamada, 2000), cause fear and anxiety (Pearson and Porath, 2005) as well as increase work withdrawal (Gabriel et al., 2018).

COR theory is extensively used to understand stress and its psychological impact (Halbesleben, 2006; Hagger, 2015). According to the COR theory, individuals tend to try their best to obtain, retain, protect and foster resources (Hobfoll, 2001). Following this logic, when newcomers are exposed to stress, they require to invest resources to cope with that stress. Naturally, this process leads to resource loss. Therefore, rather than investing resources in other tasks, resource-depleted newcomers seek to protect their remaining resources, which can lead to a decline in proactive behaviors. The application of COR theory to explain how workplace incivility toward newcomers generates resource loss and negative consequences is presented in Figure 1.

\section{Workplace incivility and proactive behaviors}

Proactive behaviors refer to future and transformative oriented actions that change the individual or existing environmental conditions (Bateman and Crant, 1993; Parker et al., 2006). Employees' proactive behaviors are outside the range of core job-related tasks, which comprise numerous positive behaviors. Following prior research (Morrison and Phelps, 1999; Van Dyne and LePine, 1998; Scott and Bruce, 1994), this paper selects three proactive behaviors that are salient in the context of newcomers and workplace incivility. These proactive behaviors are voice behavior, helping behavior and feedback-seeking behavior. Previous studies have indicated that employees' proactive behaviors can be hindered because of coworkers' negative behaviors toward them (Wu et al., 2015). Consistent with this finding, this paper posits that workplace incivility toward newcomers is negatively related to their proactive behaviors.

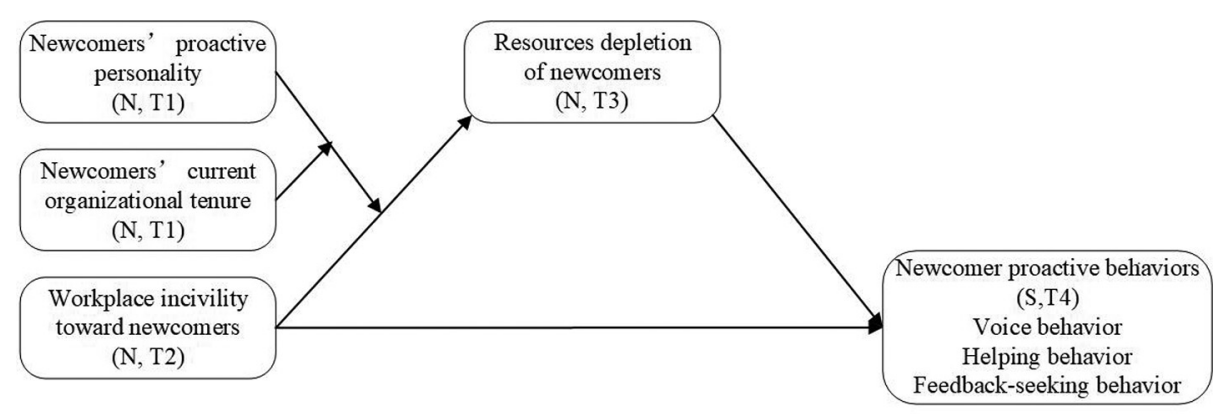

Notes: $\mathrm{N}=$ Newcomers; $\mathrm{S}=$ Supervisors. $\mathrm{T} 1=$ Time $1 ; \mathrm{T} 2=$ Time $2 ; \mathrm{T} 3=$ Time $3 ; \mathrm{T} 4=$ Time 4 
Voice behavior refers to the verbal expression of ideas, information and opinions with the prosocial motive of offering constructive contributions to change the status quo (Dyne et al., 2003). Newcomers' voice behavior can be impeded when those newcomers are targets of incivility. When newcomers experience incivility in their new workplace, they might feel uncomfortable and develop a bad impression of the organization. Thus, it may not seem possible for those newcomers to contribute to organizational aims and objectives. Furthermore, frequent incivility within the organization is not conducive to the provision of a friendly and safe environment for newcomers to engage in voice behavior. Consequently, these incivility targets are unlikely to make the effort to come up with suggestions that could be advantageous for the organization.

Helping behavior is an affiliative cooperative behavior that includes problem-solving, social perceptiveness, emotional management and support and other resource consumption behaviors (Gailliot, 2010; Dudley and Cortina, 2008). Newcomers' helping behavior will be dampened when they confront workplace incivility. On the one hand, being treated uncivilly evokes feelings of distrust and disgust towards the perpetrators. On the other hand, to protect themselves from further harm by incivility, these newcomers may seek to minimize or avoid contact with the perpetrators. Even if perpetrators are in need, these newcomers may intentionally ignore them. Hence, it is reasonable to posit that newcomers who have experienced workplace incivility will not provide helping behavior, especially when the people in need are those who are responsible for the uncivil behaviors and actions.

Feedback-seeking behavior refers to consciously devoting effort to determining what behaviors are correct and acceptable (Ashford and Cummings, 1983). This behavior is predicted to be reduced when faced with workplace incivility, which can be regarded as a type of interpersonal conflict (Sliter et al., 2012). Thus, frequently being the target of workplace incivility could make newcomers be afraid of difficulties in terms of building interpersonal relationships. Moreover, as already noted, newcomers may try to avoid dealing with the perpetrators of incivility to protect themselves. Naturally, such newcomers would not tend to seek information about how others perceive and evaluate their behavior (Ashford, 1986).

To summarize, although workplace incivility is subtle, its consequences are tangibly detrimental. Newcomers who experience frequent and varied workplace incivility from supervisors and coworkers generally evaluate their uncivil encounters and the perpetrators negatively (Cortina and Magley, 2009). Consequently, they are less likely to engage in proactive behaviors. Accordingly, the following hypothesis is put forward:

H1. Workplace incivility toward newcomers is negatively related to their voice behavior, helping behavior and feedback-seeking behavior.

\section{The mediating role of resource depletion}

Resource depletion refers to the state in which an individual's resources are decreased as a result of regulating his/her behavior, managing stress and coping with negative emotions (Muraven and Baumeister, 2000). Performing almost any behavior consumes resources. In particular, when individuals try to change the way they think, feel or behave, this process requires exertion that depletes their resources (Muraven and Baumeister, 2000). In addition, many other factors, such as psychological contract violation (Deng et al., 2017), daily surface acting (Trougakos et al., 2015), negative emotions and stress (Sasaki and Vorauer, 2010) and negative workplace behavior (Wu et al., 2015), can lead to resource depletion.

It is assumed that workplace incivility is positively related to resource depletion. COR theorists point out that stress is one of the most important reasons for employees' resource 
CMS

14,4

1040

loss and that people with higher stress are predicted to lose more resources than those with lower stress (Oaten and Cheng, 2005). Workplace incivility is an important affective factor of stress (Lim et al., 2008), and it can lead to loss of resources because employees need sustained cognitive effort to process these pressures. As a unique group in their organization, newcomers are relatively unfamiliar with the organizational environment, tasks, supervisors and coworkers. Such uncertainty and the experience of being a target of incivility may arouse nervousness and insecurity, which can gradually turn into anxiety, depression and stress. In addition, compared to seasoned workers, newcomers are more sensitive to stress. The impact of newcomers' perceived stress may be magnified, and they require to consume more resources to cope with stress. Therefore, workplace incivility from supervisors and coworkers is likely to cause resource depletion of newcomers.

According to the COR theory, resource-depleted individuals tend to take a defensive posture to avoid further resource losses (Hobfoll and Lilly, 1993) and will be less motivated to maximize their performance in different areas (Halbesleben et al., 2009). Accordingly, resource depletion is predicted to be negatively related to proactive behaviors. Engaging in voice behavior can be especially depleting for newcomers because they must not only control their rhetoric and emotional states but also anticipate and carefully respond to the emotional reactions of others (Lin and Johnson, 2015). Although newcomers are motivated to conduct voice behavior to maximize their long-term interest (Kanfer and Karoly, 1972), those in a state of depletion are more likely to invest fewer resources or even avoid investing resources in voice behavior to protect their remaining resources.

Extant research has demonstrated that giving help is a resource-costly behavior because it takes time and energy and can lead to physical and mental exhaustion (Bergeron, 2007). This behavior is not included in the job description and has no relation to formal rewards or punishments (Halbesleben and Bowler, 2007). Hence, newcomers in a state of resource depletion are reluctant to pursue helping behavior. Moreover, Trougakos et al. (2015) argued that depleted employees might determine that their remaining resources cannot be fully devoted to completing remaining work tasks and helping others and that they will consequently favor the former over the latter. Therefore, it is posited that newcomers' resource depletion will result in lower levels of helping behavior.

Employees, especially newcomers, are keen to seek feedback because it helps them attain valuable end states and valued goals such as reducing uncertainty (Ashford and Cummings, 1983) and gaining positive evaluations from supervisors and coworkers. However, this behavior is beneficial only if in-role behaviors are not neglected. Depleted newcomers will devote their remaining resources toward goals and tasks with higher reward value (Schmidt and DeShon, 2007), and put less effort into discretionary behaviors such as feedback-seeking behavior. In this context, they are motivated to protect their remaining resources and invest less psychological resources to initiate proactive behaviors. Therefore, the following hypothesis is put forward:

H2. Newcomers' resource depletion plays a mediating role between workplace incivility toward newcomers and their voice behavior, helping behavior and feedbackseeking behavior.

\section{Moderating effects of proactive personality and current organizational tenure}

Individuals with a prototypical proactive personality are relatively unconstrained by situational forces and capable of affecting changes in their environment (Bateman and Crant, 1993). Proactive individuals tend not to be passive recipients of environmental constraints on their behaviors; indeed, they are likely to intentionally and directly take 
action to change their current circumstances (Buss, 1987; Diener et al., 1984). In particular, proactive individuals identify opportunities, act on these opportunities, try their best to take action and persevere until meaningful change occurs (Crant, 1995). However, individuals who are less proactive are more passive and reactive prefer to adapt to their environment and be shaped by the world (Crant, 2000; Bakker et al., 2012).

This paper argues that proactive personality weakens the impact of workplace incivility on newcomer proactive behaviors. First, according to the COR theory, interpersonal characteristics can affect an individual's stress evaluation and help them resist stress (Hobfoll, 1989). In other words, when exposed to the same objective stress, there will be differences between people in terms of how they subjectively perceive that stress. Research by Cunningham and De La Rosa (2008) revealed that proactive personality weakens the detrimental influence of negative factors on individuals. Hence, proactive newcomers are likely to perceive less stress and do not need to spend the same amount of resources coping with stress as less proactive individuals do. Moreover, newcomers with a highly proactive personality tend to actively shape and manipulate their environment ( $\mathrm{Li}$ et al., 2010) by taking actions that help them get along with their colleagues and/or be promoted quickly. For example, they may proactively establish rapport with supervisors and coworkers, which can help them experience less workplace incivility than less proactive newcomers do. Hence, this paper hypothesizes the following:

H3. Proactive personality moderates the relationship between workplace incivility toward newcomers and their resource depletion such that this positive relationship is weaker when newcomers' proactive personality is higher rather than lower.

Although the foregoing suggests that newcomers' proactive personality would weaken the positive relationship between workplace incivility toward newcomers and their resource depletion, this relationship becomes more complex if the role of newcomers' current organizational tenure is considered. In this context, current organizational tenure refers to the amount of time employees have been working in the current organization. This paper predicts that, depending on how long newcomers have been working in the current organization, the impact of the interaction between workplace incivility toward newcomers and their proactive personality on newcomers' resource depletion will differ.

For newcomers with the same proactive personality, their current organizational tenure will influence the effect intensity of workplace incivility on their resource depletion. First, current organizational tenure magnifies the negative effect of proactive personality on workrelated stress. As noted above, proactive newcomers perceive less stress than less proactive newcomers do when they are exposed to workplace incivility. Such ability can be strengthened because the longer proactive newcomers have experienced such incivility in the new organization, they may become more experienced in handling workplace incivility. Thus, for experienced proactive newcomers, the influence of workplace incivility on resource depletion is weakened. Moreover, the longer the proactive newcomer has been employed in the new organization, the greater the opportunity they will have to leverage their abilities to change the work environment. Compared with less proactive newcomers, longer current organizational tenure helps proactive newcomers to better integrate into the new organization. These proactive newcomers will be more familiar with, and more likely to establish closer relationships with supervisors and coworkers. Thus, their ability to influence others and their work environment can also increase. This helps them reduce the likelihood that they will be targets for incivility, thus reducing the psychological resources required to deal with incivility. Therefore, this paper hypothesizes the following: 
CMS

14,4

H4. The longer newcomers work in the new organization, the stronger will be the weakening effect of proactive personality on the relationship between workplace incivility toward newcomers and their resource depletion.

According to the argument above, it is assumed herein that newcomers' resource depletion works as a mediating variable between workplace incivility toward newcomers and their proactive behaviors, including helping behavior, voice behavior and feedback-seeking behavior. Newcomers' proactive personality reduces the positive effect of workplace incivility on newcomers' resource depletion. Further, the two-way interaction effect of workplace incivility toward newcomers and their proactive personality on resource depletion will be moderated by newcomers' current organizational tenure. Hence, it is logical that the combination of newcomers' current organizational tenure and proactive personality moderates the mediating role of resource depletion, thus affecting the relationship between workplace incivility toward newcomers and their proactive behaviors. As previously mentioned, compared with their less proactive counterparts, proactive newcomers have more remaining resources after dealing with the negative effects of workplace incivility. Consequently, this process renders proactive newcomers more likely to devote more resources to proactive behaviors. The longer newcomers work in the new organization, the more likely it is that this process will be strengthened. Hence, this paper suggests that the negative indirect effect of workplace incivility on proactive behaviors via resource depletion is weaker among more experienced and highly proactive newcomers. Accordingly, the following hypothesis is posited:

H5. Workplace incivility toward newcomers will be related to their voice behavior, helping behavior and feedback-seeking behavior via conditional indirect effects such that its relationship with proactive behaviors will be mediated by newcomers' resource depletion and moderated by the combination of newcomers' current organizational tenure and proactive personality.

\section{Methods}

Sample and procedure

Data for this study came from two subsidiaries of a large food processing company located in a northern city in China. As a first step, a small number of the company's employees were randomly selected and interviewed. These interviews suggested that incivility is quite common in this company, making it a suitable research context. Following existing literature (Jokisaari and Nurmi, 2009; Liu et al., 2015), this paper defines newcomers as employees who have worked for this company for less than six months. According to the results of power analysis, the minimum sample size required for inferential analysis is 309 . A total of 400 newcomers who had been employed for less than six months and 151 corresponding supervisors voluntarily participated in the survey, and all participants were assured that their responses would be anonymous and confidential. Codes were assigned to each newcomer and his/her immediate supervisor to match supervisor-subordinate responses. After completing the questionnaire, participants were rewarded 10 yuan for each wave.

To minimize the impact of common method bias (Podsakoff et al., 2003) and for the purpose of establishing temporal precedence and deriving more robust conclusions, a supervisor-subordinate dyadic time-lagged research design was configured. Following Fida et al. (2018), a one-month interval was used between data collection points and the survey was conducted in four waves from September 2018 to December 2018. During each wave, 
the researchers distributed printed questionnaires to the participants. The respondents were required to write down their codes on the questionnaire before submission. Each completed questionnaire was then placed in a separate sealed envelope, which was collected by researchers.

Only the responses of newcomers who completed the first three waves of data collection and whose supervisors completed the survey in the fourth wave were taken forward to the analysis stage. The final sample included 322 newcomers and 132 supervisors. The response rates for newcomers and supervisors were $80.50 \%$ and $87.41 \%$, respectively. At time 1 , newcomers filled in questionnaires about the control variables and their proactive personality. At time 2, they completed surveys about workplace incivility toward them. At time 3 , they reported their resource depletion in the workplace. At time 4 , supervisors of the newcomers who had completed questionnaires at time 1,2 , and 3 evaluated the voice behavior, helping behavior and feedback-seeking behavior of the newcomers. Of the 322 newcomers, $61.80 \%$ were male $(\mathrm{SD}=0.49)$ and $87.26 \%$ held a high school diploma $(\mathrm{SD}=$ $0.39)$. The average age was 27.64 years old $(\mathrm{SD}=7.07)$ and $60.25 \%$ were plant workers $(\mathrm{SD}=0.51)$.

\section{Measures}

All scales used in this study had hitherto been published in the peer-reviewed literature. To ensure the appropriateness of the scales, a standard double-back-translation method was applied to guarantee the equivalence of meaning (Brislin, 1980). In particular, to ensure the reliability and validity of the measurement tools, two doctoral students were invited to complete the translation work. Moreover, several scholars were consulted and a subset of employees in the company were asked to verify the scale in the Chinese version. Based on feedback from these individuals, minor modifications were made to some scale items. Unless otherwise stated below, all survey items were answerable using a seven-point Likert-type scale ranging from 1 (strongly disagree) to 7 (strongly agree).

Workplace incivility. A seven-item scale developed by Cortina et al. (2001) was used to measure workplace incivility. The scale was completed by newcomers. Sample items include "Put you down or was condescending to you" and "Addressed in unprofessional terms, either publicly or privately" $(\alpha=0.903)$.

Resource depletion. A seven-item scale (Ryan and Frederick, 1997) was used to assess resource depletion. The scale was completed by newcomers. Sample items include "I feel alive and vital" and "I feel very energetic" $(\alpha=0.897)$. These positively worded items were all reverse scored.

Voice behavior. Six items from Van Dyne and Lepine (1998) were adapted to measure voice behavior. The scale was completed by newcomers' supervisors. Sample items include "This particular newcomer develops and makes recommendations concerning issues that affect this work group" and "This particular newcomer keeps well informed about issues where hihe/sher opinion might be useful to this work group" $(\alpha=0.900)$.

Helping behavior. Helping behavior was measured with seven items from Van Dyne and Lepine (1998). Newcomers' supervisors indicated whether they agree or disagree with items such as "This particular newcomer volunteers to do things for this work group" and "This particular newcomer helps orient new employees in this group" $(\alpha=0.920)$.

Feedback-seeking behavior. Five items from VandeWalle et al. (2000) were adapted to measure feedback-seeking. Newcomers' supervisors indicated how often newcomers perform certain feedback-seeking behavior at work. Sample items include "How frequently does this particular newcomer seek feedback by the inquiry method from you regarding job performance" and "How frequently does this particular newcomer seek feedback by the 
CMS

14,4

1044

inquiry method from you regarding values and attitudes of the firm" ( $\alpha=0.877)$. The scale anchors ranged from 1 (almost never) to 7 (very frequently).

Proactive personality. A ten-item scale (Seibert et al., 1999) was used to measure proactive personality. This is a shortened version of Bateman and Crant's (1993) seventeen-item scale. Newcomers assessed their personality vis-a-vis characteristics that may be used to describe a proactive person. Sample items include "I am constantly on the lookout for new ways to improve my life" and "If I see something I don't like, I fix it” ( $\alpha=0.906)$.

Current organizational tenure. Newcomers reported their current organizational tenure by answering "How many months have you been working in this company". The scale anchors ranged from 1 (less than 1 month) to 6 (less than 6 months).

Control variables. Previously, studies reported that employees' socio-demographic characteristics can affect workplace incivility toward them. For example, individuals who are comparatively young, female, and have less powerful positions within organizations, are more likely to endure incivility than those who are older, male and in more powerful positions within organizations (Cortina et al., 2001; Lim and Lee, 2011). Thus, age, gender, education and position of newcomers were used as control variables.

\section{Results}

Confirmatory factor analysis

To examine the validity of the six key constructs, several confirmatory factor analyses (CFA) were conducted using AMOS 22.0. First, a six-factor CFA model was examined, including workplace incivility, resource depletion, proactive personality, voice behavior, helping behavior and feedback-seeking behavior. Chi-square, the Tucker-Lewis index (TLI), the comparative fit index (CFI), the root mean square error of approximation (RMSEA) and the standardized root mean residual (SRMR) were used to assess model fit. The results revealed that the six-factor model fit the data well $\left(\chi^{2}=1480.973, d f=804, T L I=0.917\right.$, $C F I=0.922, R M S E A=0.051, S R M R=0.050)$ and all factor loadings were significant.

To determine the discriminant validity of the six constructs, competing models were constructed. As shown in Table 1, the six-factor model fits the data better than other competing models, indicating that the proposed six constructs have good discriminant validity. Therefore, these six constructs were used in the subsequent data analysis.

\section{Descriptive analyses}

Means, standard deviations, zero-order Pearson correlations and scale reliabilities for each variable are shown in Table 2. Workplace incivility toward newcomers is positively correlated with resource depletion $(r=0.642, p<0.01)$, and negatively correlated with voice behavior $(r=-0.516, p<0.01)$, helping behavior $(r=-0.410, p<0.01)$ and feedbackseeking behavior $(r=-0.193, p<0.01)$. Moreover, resource depletion is negatively correlated with voice behavior $(r=-0.640, p<0.01)$, helping behavior $(r=-0.525, p<0.01)$ and feedback-seeking behavior $(r=-0.358, p<0.01)$. These results provide preliminary support for the study's hypotheses.

\section{Hypotheses testing}

Linear regression analysis is utilized to test H1. After controlling for the effects of age, gender, education and position (these variables were controlled consistently during hypothesis testing), significant negative effects of workplace incivility toward newcomers on their voice behavior $(\beta=-0.509, p<0.01)$, helping behavior $(\beta=-0.417, p<0.01)$ and 


\begin{tabular}{|c|c|c|c|c|c|c|c|}
\hline Model & $x^{2}$ & $\mathrm{df}$ & TLI & CFI & RMSEA & SRMR & $\begin{array}{l}\text { Proactive } \\
\text { behaviors }\end{array}$ \\
\hline \multirow{11}{*}{$\begin{array}{l}\text { Six-factor Model } \\
\text { Five-factor Model } 1 \text { combining workplace incivility } \\
\text { toward newcomers and resource depletion } \\
\text { Five-factor Model } 2 \text { combining workplace incivility } \\
\text { toward newcomers and proactive personality } \\
\text { Five-factor Model } 3 \text { combining resource depletion } \\
\text { and proactive personality } \\
\text { Five-factor Model } 4 \text { combining resource depletion } \\
\text { and voice behavior } \\
\text { Five-factor Model } 5 \text { combining resource depletion } \\
\text { and helping behavior } \\
\text { Five-factor Model } 6 \text { combining helping behavior and } \\
\text { feedback-seeking behavior } \\
\text { Four-factor Model } 1 \text { combining resource depletion, } \\
\text { helping behavior, and feedback-seeking behavior } \\
\text { Four-factor Model } 2 \text { combining workplace incivility } \\
\text { toward newcomers, resource depletion, and voice } \\
\text { behavior } \\
\text { Three-factor Model combining workplace incivility } \\
\text { toward newcomers and resource depletion, } \\
\text { combining voice behavior, helping behavior and } \\
\text { feedback-seeking behavior } \\
\text { One-factor Model }\end{array}$} & 1480.973 & 804 & 0.917 & 0.922 & 0.051 & 0.050 & \\
\hline & 1931.513 & 809 & 0.863 & 0.871 & 0.066 & 0.059 & \\
\hline & & & & & & & \\
\hline & 2604.106 & 809 & 0.781 & 0.794 & 0.083 & 0.106 & 1045 \\
\hline & 1971.431 & 809 & 0.858 & 0.867 & 0.067 & 0.063 & \\
\hline & 2339.523 & 809 & 0.813 & 0.824 & 0.077 & 0.069 & \\
\hline & 2227.716 & 809 & 0.827 & 0.837 & 0.074 & 0.076 & \\
\hline & 3006.018 & 813 & 0.734 & 0.749 & 0.092 & 0.087 & \\
\hline & 2491.208 & 813 & 0.796 & 0.808 & 0.080 & 0.078 & \\
\hline & & & & & & 0.081 & $\begin{array}{r}\text { Table 1. } \\
\text { Results of } \\
\text { onfirmatory factor }\end{array}$ \\
\hline & & 819 & 0.506 & & & 0.126 & \\
\hline
\end{tabular}

feedback-seeking behavior $(\beta=-0.180, p<0.01)$ were revealed. Thus, $H 1 a, H 1 b$ and $H 1 c$ were supported.

All remaining hypotheses were tested using the PROCESS macro in SPSS version 22 (Hayes, 2013) with a 5000-resample bootstrap method to construct 95\% bias-corrected confidence intervals (CIs). If the CI did not include 0 , the null hypothesis of no (conditional) indirect effect was rejected (Preacher et al., 2007).

To test H2, PROCESS model 4 was executed. As shown in Table 3, there are significant mediation effects from resource depletion on the relationship between workplace incivility toward newcomers and their proactive behaviors. For voice behavior, the $95 \% \mathrm{CI}$ of the indirect effect is -0.433 to -0.226 for helping behavior, the $95 \% \mathrm{CI}$ of the indirect effect is -0.401 to -0.186 , and for feedback-seeking behavior, the $95 \% \mathrm{CI}$ of the indirect effect is 0.384 to -0.171 . Thus, $H 2 a, H 2 b$ and $H 2 c$ were supported.

PROCESS model 1 was executed to test H3. Specifically, in PROCESS model 1 , one moderator $(\mathrm{M})$ moderates the relationship between the independent variable $(\mathrm{X})$ and dependent variable $(\mathrm{Y})$. As shown in Table 4, it was revealed that the interaction between workplace incivility toward newcomers and proactive personality is negatively related to newcomers' resource depletion $(\beta=-0.169, S E=0.054, p<0.01)$. Thus, $H 3$ was supported.

To further test the moderating effect, a simple slope analysis (Aiken et al., 1991) was carried out, demarcating between high (one standard deviation above the mean) and low (one standard deviation below the mean) levels of proactive personality. As shown in Figure 2, the influence of workplace incivility on resource depletion is weaker for more proactive individuals than for less proactive individuals.

In PROCESS model 3, the combination of two moderators ( $\mathrm{M}$ and $\mathrm{W}$ ) moderates the relationship between the independent variable $(\mathrm{X})$ and dependent variable $(\mathrm{Y})$. Thus, PROCESS model 3 was run to test H4. As shown in Table 5, the interaction between 
CMS

14,4

1046

Table 2.

Means, standard deviations, and correlations

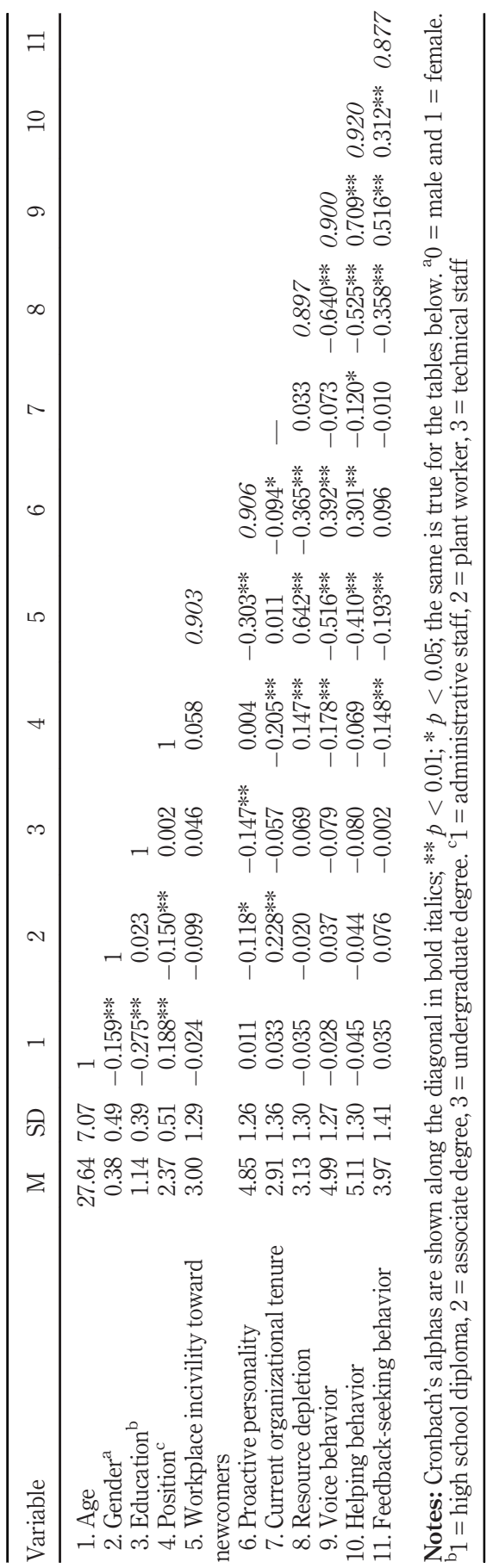


workplace incivility toward newcomers, proactive personality and current organizational tenure is negatively related to newcomers' resource depletion $(\beta=-0.081, S E=0.038, p<$ 0.01). Thus, $H 4$ was supported.

Next, a graph of the three-way interaction effect was plotted, following Aiken et al. (1991). As shown in Figure 3, the relationship between workplace incivility toward newcomers and their resource depletion was weakest when newcomers had high proactive personality and long current organizational tenure. This relationship was strongest when newcomers had low proactive personality and long current organizational tenure.

To test H5 and control the potential influence of proactive personality on proactive behaviors, PROCESS model 13 was executed. Model 13 is able to test the conditional mediation effects of moderator 1 and moderator 2 at two levels ( +1 SD and -1 SD). As shown in Table 6 , the combination of proactive personality and current organizational tenure moderated the indirect effects of workplace incivility toward newcomers on voice behavior, helping behavior and feedback-seeking behavior via resource depletion. Specifically, resource depletion had the strongest mediation effect on the relationship between workplace incivility toward newcomers and voice behavior with proactive personality at $-1 \mathrm{SD}$ and current organizational tenure at $+1 \mathrm{SD}$ (i.e. indirect effect $=-0.341,95 \% \mathrm{CI}=[-0.526,-0.211])$. The mediation effect was weakest with proactive personality at $+1 \mathrm{SD}$ and current organizational tenure at $+1 \mathrm{SD}$ (i.e. indirect effect $=-0.073,95 \% \mathrm{CI}=[-0.161,0.001]$, n.s.). Resource depletion exhibited the strongest mediation effect on the relationship between workplace incivility toward newcomers and helping behavior with proactive personality at $-1 \mathrm{SD}$ and current organizational tenure at $+1 \mathrm{SD}$ (i.e. indirect effect $=-0.345,95 \% \mathrm{CI}=[-0.558,-0.199]$ ). The mediation effect was weakest with proactive personality at $+1 \mathrm{SD}$ and current organizational tenure at $+1 \mathrm{SD}$ (i.e. indirect effect $=-0.074,95 \% \mathrm{CI}=[-0.162,0.000]$, n.s.). Moreover, resource depletion

\begin{tabular}{llcccc}
\hline Variable & & Effect & Boot SE & Boot LL 95\% CI & Boot UL 95\% CI \\
\hline Voice behavior & Direct effect & -0.183 & 0.054 & -0.29 & -0.077 \\
Helping behavior & Indirect effect & -0.320 & 0.052 & -0.433 & -0.226 \\
& Direct effect & -0.137 & 0.056 & -0.247 & -0.028 \\
Feedback-seeking behavior & Indirect effect & -0.284 & 0.055 & -0.401 & -0.186 \\
& Direct effect & 0.074 & 0.073 & -0.070 & 0.217 \\
& Indirect effect & -0.271 & 0.054 & -0.384 & -0.171
\end{tabular}

Notes: all coefficients are unstandardized. Boot = bootstrapped estimate. $\mathrm{SE}=$ standard error. $\mathrm{LL}=$ lower level. UL = upper level. $\mathrm{CL}=$ confidence interval
Proactive behaviors

1047

\section{$-2$}


CMS

14,4

1048

had the strongest mediation effect on the relationship between workplace incivility toward newcomers and feedback-seeking behavior with proactive personality at $-1 \mathrm{SD}$ and current organizational tenure at $+1 \mathrm{SD}$ (i.e. indirect effect $=-0.348,95 \% \mathrm{CI}=[-0.541,-0.201]$ ). The mediation effect was weakest with proactive personality at $+1 \mathrm{SD}$ and current organizational tenure at $+1 \mathrm{SD}$ (i.e. indirect effect $=-0.074,95 \% \mathrm{CI}=[-0.172,0.002]$, n.s.). Thus, $H 5$ was supported.

Moreover, results with and without control variables were compared; it was revealed that whether or not such variables are included does not change the conclusion.

\section{Discussion}

Drawing on COR theory, the current research proposed and tested a three-way moderated mediation model to understand the mechanisms through which workplace incivility toward newcomers affects their proactive behaviors. Through a time-lagged (four-wave) and multi-source (supervisor and employee) research design, it was revealed that workplace incivility toward newcomers positively affected resource depletion and indirectly affected newcomer proactive behaviors via resource depletion. This study gleaned information about the boundary conditions under which the detrimental effect of workplace incivility on proactive behaviors is moderated. The empirical results showed

Figure 2.

The moderated effect of newcomers' proactive personality on the relationship between workplace incivility toward newcomers and resource depletion

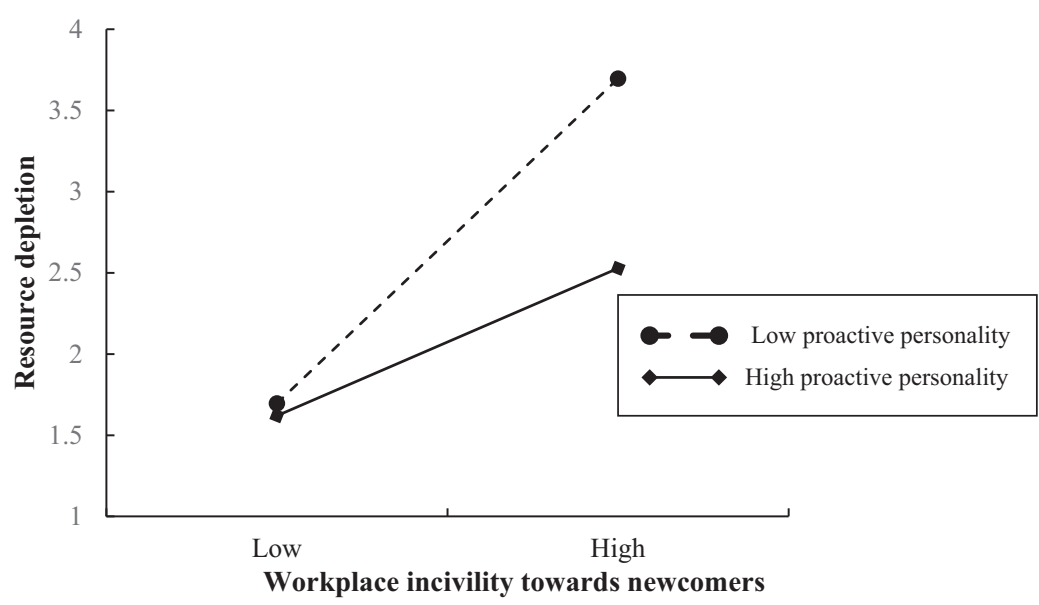

\begin{tabular}{lrccr}
\hline Variable & Effect & SE & Boot LL 95\% CI & Boot UL 95\% CI \\
\hline Y: Resource depletion & & & & \\
Constant & 2.343 & 0.365 & 1.625 & 3.061 \\
M: Proactive personality & -0.252 & 0.049 & -0.349 & -0.155 \\
W: Current organizational tenure & 0.011 & 0.039 & -0.065 & 0.087 \\
X: Workplace incivility toward newcomers & 0.559 & 0.052 & 0.457 & 0.662 \\
Interaction: $\mathrm{X} \times \mathrm{M}$ & -0.175 & 0.050 & -0.274 & -0.076 \\
Interaction: $\mathrm{X} \times \mathrm{W}$ & -0.005 & 0.043 & -0.089 & 0.079 \\
Interaction: $\mathrm{M} \times \mathrm{W}$ & -0.064 & 0.036 & -0.136 & 0.007 \\
Interaction: $\mathrm{X} \times \mathrm{M} \times \mathrm{W}$ & -0.081 & 0.038 & -0.157 & -0.005 \\
\hline
\end{tabular}

Interaction: $\mathrm{X} \times \mathrm{M} \times \mathrm{W}$
Table 5.

H4 Current

organizational tenure as a moderator in the three-way interaction framework 
that the indirect effect of workplace incivility on proactive behaviors was stronger for newcomers with a less proactive personality and longer current organizational tenure.

\section{Theoretical implications}

This paper has important theoretical contributions. The first contribution concerns the explication of resource depletion as a key mechanism through which workplace incivility from supervisors and coworkers influences newcomer proactive behaviors. The literature is lacking in terms of studies paying attention to the psychological resource states of incivility targets. Although several studies have applied COR theory to understand the consequences of workplace incivility (Zhou et al., 2015; Hur et al., 2015), research on the mediating role of resource depletion is lacking. Grounded in COR theory, this study finds that resource depletion serves as a bridge linking workplace incivility to newcomer proactive behaviors, thereby unpacking the "black box" of how workplace incivility influences newcomer proactive behaviors.

Second, this research enriches incivility studies in the context of newcomers. Obviously, newcomers' successful socialization is crucial to organizational development. Previous studies concerning newcomers' organizational socialization mainly concentrate on the impact of positive factors (Morrison, 2002; Bauer et al., 2007; Bauer et al., 2019). However, it is possible that newcomers may encounter negative behaviors in the workplace such as gossip, incivility, bullying, aggression and violence. These experiences could slow down or even thwart the socialization of newcomers. The results generated herein show that newcomers who are victims of incivility may have reduced voice behavior, helping behavior and feedback-seeking behavior because their resources are depleted. Accordingly, this paper provides a new perspective to further understand and study newcomers' behavior.

Third, this research extends the study of incivility by exploring the moderating effects of proactive personality and current organizational tenure on the relationship between workplace incivility toward newcomers and their resource depletion and on the mediating effect of resource depletion on the relationship between workplace incivility and proactive behaviors. In particular, the findings suggest that both of these effects are significant and strongest when newcomers have high proactive personality and long current organizational

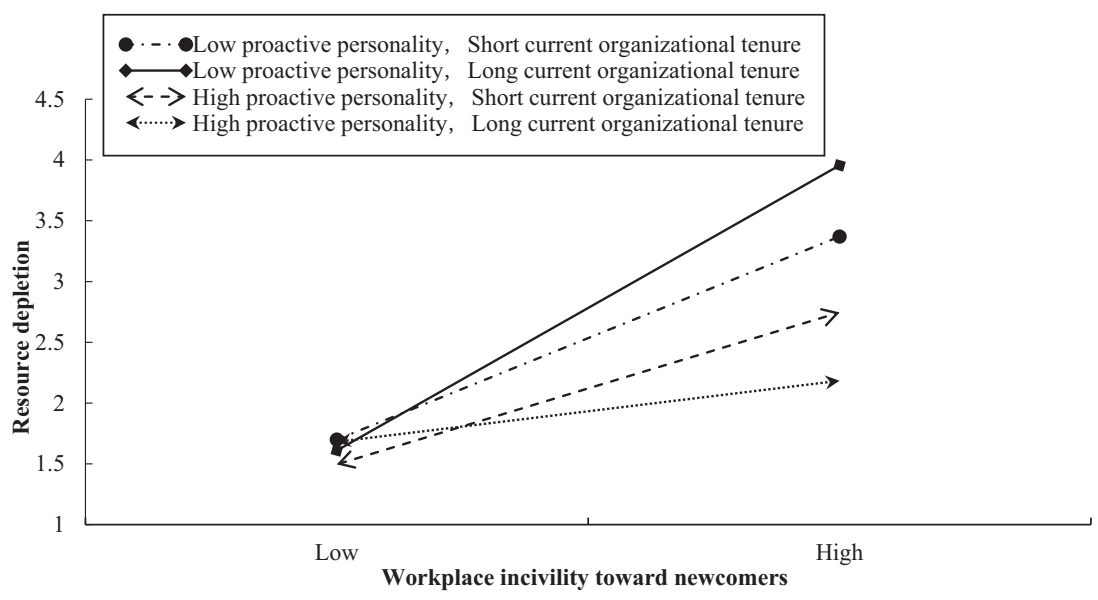

Figure 3.

The three-way interaction effects (workplace incivility toward newcomers $x$ proactive personality $x$ current organizational tenure) on newcomers' resource depletion 
CMS

14,4

1050

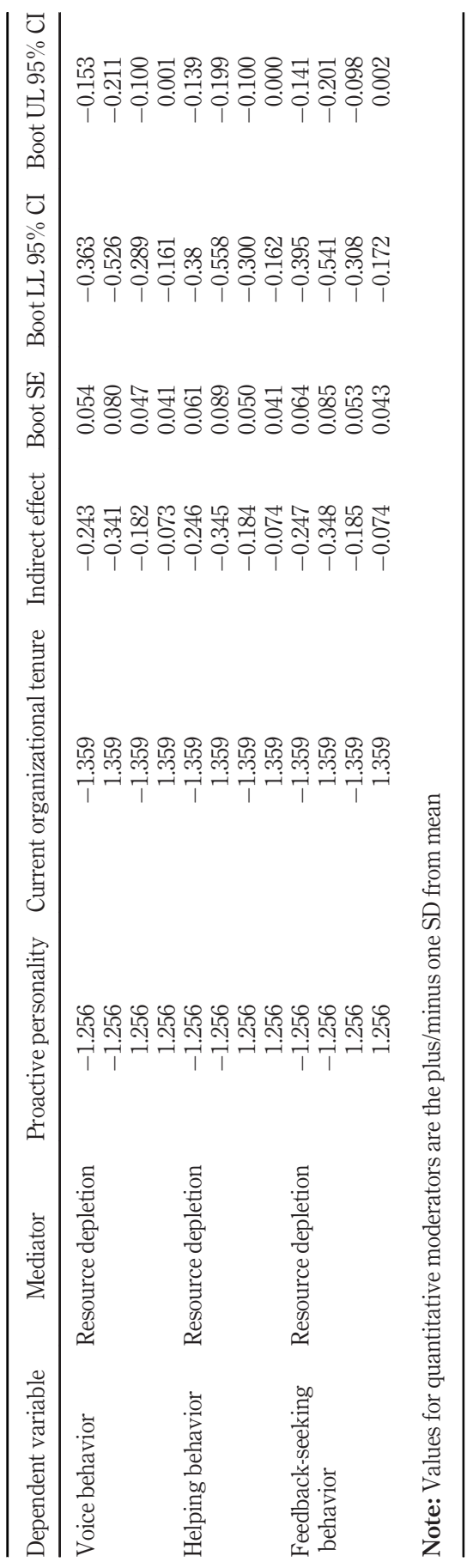

Table 6.

H5 Newcomers'

resource depletion as the mediator in conditional indirect effects models 
tenure, and are insignificant when newcomers have low proactive personality and long current organizational tenure. Therefore, this study not only extends prior research on the moderators of workplace incivility and newcomer proactive behaviors relationship but also reinforces the importance of employees' current organizational tenure in facilitating or hindering the effect of incivility on its potential targets.

\section{Practical implications}

This study offers several practical implications. First, this research could help managers obtain deep insight into workplace incivility, which negatively impacts newcomers' mental health and behavior and causes substantive losses to organizations (Duhart, 2001). Therefore, managers should develop appropriate measures to reduce workplace incivility. For example, before recruiting new employees, human resource departments could develop explicit operational procedures to avoid hiring discourteous individuals. Furthermore, managers should establish specific criteria for acceptable behavior and encourage mutual respect and concern among employees. In this way, employees can be made aware of what behaviors are inappropriate and prohibited in the workplace.

Second, this study could improve managers' understanding of newcomers who constitute an essential element in organizations. Workplace incivility toward newcomers can lead to resource depletion, which in turn discourages their proactive behaviors. Managers should be more concerned about the mental health of newcomers and give sufficient psychological support to newcomers who have suffered from workplace incivility. Managers could spend more time with newcomers to learn about their psychological state and communicate with them regularly if necessary. In this way, newcomers' resource losses caused by unexpected conflicts might be restored to some extent (Fredrickson and Branigan, 2005).

Finally, the results revealed that newcomers' proactive personality could moderate the relationship between workplace incivility and resource depletion. Existing studies point out that proactive personality is positively related to employee performance and career success (Seibert et al., 1999; Bakker et al., 2012). Accordingly, managers should consider proactive personality as part of a broader set of criteria for selecting and promoting employees (Li et al., 2010; Bakker et al., 2012). By extension, managers should provide a supportive work environment to increase personality-environment fit (Ostroff and Judge, 2007). In doing so, more highly proactive individuals can be attracted or retained by organizations (Li et al., 2014).

\section{Limitations and future research}

In common with applied research more generally, this study is not without its limitations. First, the COR theory guides us to believe that workplace incivility negatively impacts proactive behavior via resource depletion. The multi-wave measurements and empirical analysis help demonstrate such an argument. However, the design does not allow for causal influence. More specifically, the current research did not control the baseline of employee proactive behaviors, and the causal influence between workplace incivility and proactive behaviors might be mixed up. Future research could adopt a panel design or experimental studies to further investigate the above relationships.

Second, this study used a time-lagged (four-wave) and multi-source (supervisor and employee) research design, which helps minimize common method bias. However, the study was only conducted in a Chinese context. The idea that "harmony is precious" in traditional Chinese culture might drive employees to conceal negative information from their organization. Moreover, the survey respondents were employees in one company. Although this helped to control the influence of industries, laws/regulations and corporate culture, it 
CMS

14,4

could mean that external validity is hampered. As such, future studies should explore the influence of workplace incivility on newcomer proactive behaviors in diverse industries (such as medical, education and services) and alternative country settings.

Third, this study investigated the moderating roles of proactive personality and current organizational tenure on the relationship between workplace incivility and proactive behaviors. There may be other factors that influence workplace incivility and its potential effects. For example, future research could further explore possible boundary conditions from the perspective of organizational culture, similarity of incivility targets and perpetrators and gender of incivility targets. Furthermore, although this study emphasizes the difference between newcomers and seasoned employees, such differences were not statistically tested. Future research could, therefore, explore the moderating effect of newcomers' and seasoned employees' current organizational tenure on the relationship between workplace incivility toward newcomers and work-related outcomes.

Fourth, this study defined employees who have worked for the current company for less than six months as newcomers. Thus, regardless of whether the employee is a recent graduate who just entered the workplace or whether they have worked for other organizations for many years, as long as her/his tenure in the new organization is within six months, he/she is a newcomer. However, when recent graduates suffer incivility, they may be more stressed and nervous than the latter group. This study did not distinguish between these two groups and, as such, future research could go one step further and investigate the moderating effect of these differences.

\section{References}

Abubakar, A.M. (2018), "Linking work-family interference, workplace incivility, gender and psychological distress", Journal of Management Development, Vol. 37 No. 3, pp. 226-242.

Aiken, L.S., West, S.G. and Reno, R.R. (1991), Multiple Regression: Testing and Interpreting Interactions, Sage Publications, Los Angeles.

Andersson, L.M. and Pearson, C.M. (1999), "Tit for tat? The spiraling effect of incivility in the workplace", The Academy of Management Review, Vol. 24 No. 3, pp. 452-471.

Ashford, S.J. (1986), "Feedback-seeking in individual adaptation: a resource perspective", Academy of Management Journal, Vol. 29 No. 3, pp. 465-487.

Ashford, S.J. and Cummings, L.L. (1983), "Feedback as an individual resource: personal strategies of creating information", Organizational Behavior and Human Performance, Vol. 32 No. 3, pp. 370-398.

Bakker, A.B., Tims, M. and Derks, D. (2012), "Proactive personality and job performance: the role of job crafting and work engagement”, Human Relations, Vol. 65 No. 10, pp. 1359-1378.

Bateman, T.S. and Crant, J.M. (1993), "The proactive component of organizational behavior: a measure and correlates", Journal of Organizational Behavior, Vol. 14 No. 2, pp. 103-118.

Bauer, T.N., Bodner, T., Erdogan, B., Truxillo, D.M. and Tucker, J.S. (2007), “Newcomer adjustment during organizational socialization: a meta-analytic review of antecedents, outcomes, and methods", Journal of Applied Psychology, Vol. 92 No. 3, pp. 707-721.

Bauer, T.N., Perrot, S., Liden, R.C. and Erdogan, B. (2019), "Understanding the consequences of newcomer proactive behaviors: the moderating contextual role of servant leadership", Journal of Vocational Behavior, Vol. 112, pp. 356-368.

Bergeron, D.M. (2007), “The potential paradox of organizational citizenship behavior: good citizens at what cost?", Academy of Management Review, Vol. 32 No. 4, pp. 1078-1095. 
Brislin, R.W. (1980), "Translation and content analysis of oral and written material. HC Triandis ve JW Berry (Der.)", Handbook of Cross-Cultural Psychology, pp. 389-444.

Buss, D.M. (1987), "Selection, evocation, and manipulation", Journal of Personality and Social Psychology, Vol. 53 No. 6, pp. 1214-1221.

Cortina, L.M. and Magley, V.J. (2009), "Patterns and profiles of response to incivility in the workplace", Journal of Occupational Health Psychology, Vol. 14 No. 3, pp. 272-288.

Cortina, L.M., Magley, V.J., Williams, J.H. and Langhout, R.D. (2001), "Incivility in the workplace: incidence and impact", Journal of Occupational Health Psychology, Vol. 6 No. 1, pp. 64-80.

Crant, J.M. (1995), "The proactive personality scale and objective job performance among real estate agents", Journal of Applied Psychology, Vol. 80 No. 4, pp. 532-537.

Crant, J.M. (2000), "Proactive behavior in organizations", Journal of Management, Vol. 26 No. 3, pp. 435-462.

Cunningham, C.J. and De La Rosa, G.M. (2008), "The interactive effects of proactive personality and work-family interference on well-being", Journal of Occupational Health Psychology, Vol. 13 No. 3, pp. 271-282.

De Cuyper, N., Mäkikangas, A., Kinnunen, U., Mauno, S. and Witte, H.D. (2012), “Cross-lagged associations between perceived external employability, job insecurity, and exhaustion: testing gain and loss spirals according to the conservation of resources theory", Journal of Organizational Behavior, Vol. 33 No. 6, pp. 770-788.

Deng, H., Coyle-Shapiro, J. and Yang, Q. (2017), "Beyond reciprocity: a conservation of resources view on the effects of psychological contract violation on third parties", Journal of Applied Psychology, Vol. 103 No. 5, pp. 561-577.

Diener, E., Larsen, R.J. and Emmons, R.A. (1984), "Person $\times$ situation interactions: choice of situations and congruence response models", Journal of Personality and Social Psychology, Vol. 47 No. 3, pp. 580-592.

Dudley, N.M. and Cortina, J.M. (2008), "Knowledge and skills that facilitate the personal support dimension of citizenship", Journal of Applied Psychology, Vol. 93 No. 6, pp. 1249-1270.

Duhart, D.T. (2001), Violence in the Workplace, 1993-99, US Department of Justice, Office of Justice Programs, Washington, DC.

Dyne, L.V., Ang, S. and Botero, I.C. (2003), "Conceptualizing employee silence and employee voice as multidimensional constructs", Journal of Management Studies, Vol. 40 No. 6, pp. 1359-1392.

Ellis, A.M., Nifadkar, S.S., Bauer, T.N. and Erdogan, B. (2017), "Newcomer adjustment: examining the role of managers' perception of newcomer proactive behavior during organizational socialization", Journal of Applied Psychology, Vol. 102 No. 6, pp. 993-1001.

Fida, R., Laschinger, H.K.S. and Leiter, M.P. (2018), "The protective role of self-efficacy against workplace incivility and burnout in nursing: a time-lagged study", Health Care Management Review, Vol. 43 No. 1, pp. 21-29.

Fredrickson, B.L. and Branigan, C. (2005), "Positive emotions broaden the scope of attention and thought-action repertoires", Cognition and Emotion, Vol. 19 No. 3, pp. 313-332.

Gabriel, A.S., Butts, M.M., Yuan, Z., Rosen, R.L. and Sliter, M.T. (2018), "Further understanding incivility in the workplace: the effects of gender, agency, and communion", Journal of Applied Psychology, Vol. 103 No. 4, pp. 362-382.

Gailliot, M.T. (2010), "The effortful and energy-demanding nature of prosocial behavior", in Mikulincer, M. and Shaver, P.R. (Eds), Prosocial Motives, Emotions, and Behavior: The Better Angels of Our Nature, American Psychological Association, Washington, DC, pp. 169-180.

Giumetti, G.W., Hatfield, A.L., Scisco, J.L., Schroeder, A.N., Muth, E.R. and Kowalski, R.M. (2013), "What a rude e-mail! examining the differential effects of incivility versus support on mood, energy, engagement, and performance in an online context", Journal of Occupational Health Psychology, Vol. 18 No. 3, pp. 297-309. 
CMS

14,4

1054

Grandey, A.A. and Cropanzano, R. (1999), "The conservation of resources model applied to workfamily conflict and strain”, Journal of Vocational Behavior, Vol. 54 No. 2, pp. 350-370.

Gruman, J.A., Saks, A.M. and Zweig, D.I. (2006), "Organizational socialization tactics and newcomer proactive behaviors: an integrative study", Journal of Vocational Behavior, Vol. 69 No. 1, pp. 90-104.

Hagger, M.S. (2015), “Conservation of resources theory and the 'strength' model of self-control: conceptual overlap and commonalities", Stress and Health, Vol. 31 No. 2, pp. 89-94.

Halbesleben, J.R. (2006), "Sources of social support and burnout: a meta-analytic test of the conservation of resources model", Journal of Applied Psychology, Vol. 91 No. 5, pp. 1134-1145.

Halbesleben, J.R. and Bowler, W.M. (2007), "Emotional exhaustion and job performance: the mediating role of motivation", Journal of Applied Psychology, Vol. 92 No. 1, pp. 93-106.

Halbesleben, J.R., Harvey, J. and Bolino, M.C. (2009), "Too engaged? A conservation of resources view of the relationship between work engagement and work interference with family", Journal of Applied Psychology, Vol. 94 No. 6, pp. 1452-1465.

Hayes, A.F. (2013), Introduction to Mediation, Moderation, and Conditional Process Analysis: A Regression-Based Approach, Guilford Press, London.

Hershcovis, M.S., Ogunfowora, B., Reich, T.C. and Christie, A.M. (2017), "Targeted workplace incivility: the roles of belongingness, embarrassment, and power", Journal of Organizational Behavior, Vol. 38 No. 7, pp. 1057-1075.

Hobfoll, S.E. (1989), "Conservation of resources: a new attempt at conceptualizing stress", American Psychologist, Vol. 44 No. 3, pp. 513-524.

Hobfoll, S.E. (2001), "The influence of culture, community, and the nested-self in the stress process: advancing conservation of resources theory", Applied Psychology, Vol. 50 No. 3, pp. 337-421.

Hobfoll, S.E. and Freedy, J. (1993), "Conservation of resources: a general stress theory applied to burnout", in Schaufeli, W.B., Maslach, C. and Marek, T. (Eds), Professional Burnout: Recent Developments in Theory and Research. Series in Applied Psychology: Social Issues and Questions, Taylor and Francis, Philadelphia, PA, pp. 115-133.

Hobfoll, S.E. and Lilly, R.S. (1993), "Resource conservation as a strategy for community psychology", Journal of Community Psychology, Vol. 21 No. 2, pp. 128-148.

Hobfoll, S.E. and Shirom, A. (2001), "Conservation of resources theory: applications to stress and management in the workplace", in Golembiewski, R.T. (Ed.), Handbook of Organizational Behavior, Marcel Dekker, New York, NY, pp. 57-80.

Hur, W.M., Kim, B.S. and Park, S.J. (2015), "The relationship between coworker incivility, emotional exhaustion, and organizational outcomes: the mediating role of emotional exhaustion", Human Factors and Ergonomics in Manufacturing and Service Industries, Vol. 25 No. 6, pp. 701-712.

Jokisaari, M. and Nurmi, J.E. (2009), "Change in newcomers' supervisor support and socialization outcomes after organizational entry", Academy of Management Journal, Vol. 52 No. 3, pp. 527-544.

Kanfer, F.H. and Karoly, P. (1972), "Self-control: a behavioristic excursion into the lion's den”, Behavior Therapy, Vol. 3 No. 3, pp. 398-416.

Li, W.D., Fay, D., Frese, M., Harms, P.D. and Gao, X.Y. (2014), "Reciprocal relationship between proactive personality and work characteristics: a latent change score approach", Journal of Applied Psychology, Vol. 99 No. 5, pp. 948-965.

Li, N., Liang, J. and Crant, J.M. (2010), "The role of proactive personality in job satisfaction and organizational citizenship behavior: a relational perspective", Journal of Applied Psychology, Vol. 95 No. 2, pp. 395-404.

Lim, S. and Cortina, L.M. (2005), "Interpersonal mistreatment in the workplace: the interface and impact of general incivility and sexual harassment", Journal of Applied Psychology, Vol. 90 No. 3, pp. 483-496. 
Lim, S., Cortina, L.M. and Magley, V.J. (2008), "Personal and workgroup incivility: impact on work and health outcomes", Journal of Applied Psychology, Vol. 93 No. 1, pp. 95-107.

Lim, S., Ilies, R., Koopman, J., Christoforou, P. and Arvey, R.D. (2016), "Emotional mechanisms linking incivility at work to aggression and withdrawal at home: an experience-sampling study", Journal of Management, Vol. 44 No. 7, pp. 2888-2908.

Lim, S. and Lee, A. (2011), "Work and nonwork outcomes of workplace incivility: does family support help?”, Journal of Occupational Health Psychology, Vol. 16 No. 1, pp. 95-111.

Lin, S.H.J. and Johnson, R.E. (2015), "A suggestion to improve a day keeps your depletion away: examining promotive and prohibitive voice behaviors within a regulatory focus and resource depletion framework", Journal of Applied Psychology, Vol. 100 No. 5, pp. 1381-1397.

Liu, S., Wang, M., Bamberger, P., Shi, J. and Bacharach, S.B. (2015), "The dark side of socialization: a longitudinal investigation of newcomer alcohol use", Academy of Management Journal, Vol. 58 No. 2, pp. 334-355.

Morrison, E.W. (2002), "Newcomers' relationships: the role of social network ties during socialization", Academy of Management Journal, Vol. 45 No. 6, pp. 1149-1160.

Morrison, E.W. and Phelps, C.C. (1999), "Taking charge at work: extrarole efforts to initiate workplace change", Academy of Management Journal, Vol. 42 No. 4, pp. 403-419.

Muraven, M. and Baumeister, R.F. (2000), "Self-regulation and depletion of limited resources: does selfcontrol resemble a muscle?”, Psychological Bulletin, Vol. 126 No. 2, pp. 247-259.

Oaten, M. and Cheng, K. (2005), “Academic examination stress impairs self-control”, Journal of Social and Clinical Psychology, Vol. 24 No. 2, pp. 254-279.

Ostroff, C.L. and Judge, T. (2007), Perspectives on Organizational Fit, Psychology Press, East Sussex.

Parker, S.K., Williams, H.M. and Turner, N. (2006), "Modeling the antecedents of proactive behavior at work", Journal of Applied Psychology, Vol. 91 No. 3, pp. 636-652.

Pearson, C.M. and Porath, C.L. (2005), "On the nature, consequences and remedies of workplace incivility: no time for 'nice'? Think again", Academy of Management Perspectives, Vol. 19 No. 1, pp. 7-18.

Pearson, C.M., Andersson, L.M. and Porath, C.L. (2000), "Assessing and attacking workplace incivility”, Organizational Dynamics, Vol. 29 No. 2, pp. 123-137.

Penney, L.M. and Spector, P.E. (2005), "Job stress, incivility, and counterproductive work behavior (CWB): the moderating role of negative affectivity", Journal of Organizational Behavior, Vol. 26 No. 7, pp. 777-796.

Podsakoff, P.M., MacKenzie, S.B., Lee, J.Y. and Podsakoff, N.P. (2003), "Common method biases in behavioral research: a critical review of the literature and recommended remedies", Journal of Applied Psychology, Vol. 88 No. 5, pp. 879-903.

Porath, C.L. and Pearson, C.M. (2012), "Emotional and behavioral responses to workplace incivility and the impact of hierarchical status", Journal of Applied Social Psychology, Vol. 42, pp. E326-E357.

Porath, C.L. and Pearson, C.M. (2013), "The price of incivility: lack of respect hurts morale-and the bottom line", Harvard Business Review, Vol. 91, pp. 114-121.

Preacher, K.J., Rucker, D.D. and Hayes, A.F. (2007), "Addressing moderated mediation hypotheses: theory, methods, and prescriptions", Multivariate Behavioral Research, Vol. 42 No. 1, pp. 185-227.

Rahim, A. and Cosby, D.M. (2016), "A model of workplace incivility, job burnout, turnover intentions, and job performance", Journal of Management Development, Vol. 35 No. 10, pp. 1255-1265.

Ryan, R.M. and Frederick, C. (1997), "On energy, personality, and health: subjective vitality as a dynamic reflection of well-being", Journal of Personality, Vol. 65 No. 3, pp. 529-565.

Sasaki, S.J. and Vorauer, J.D. (2010), "Contagious resource depletion and anxiety? Spreading effects of evaluative concern and impression formation in dyadic social interaction", Journal of Experimental Social Psychology, Vol. 46 No. 6, pp. 1011-1016. 
CMS

14,4

1056

Schilpzand, P., De Pater, I.E. and Erez, A. (2016), "Workplace incivility: a review of the literature and agenda for future research”, Journal of Organizational Behavior, Vol. 37, pp. 57-88.

Schmidt, A.M. and DeShon, R.P. (2007), "What to do? The effects of discrepancies, incentives, and time on dynamic goal prioritization", Journal of Applied Psychology, Vol. 92 No. 4, pp. 928-941.

Scott, S.G. and Bruce, R.A. (1994), "Determinants of innovative behavior: a path model of individual innovation in the workplace", Academy of Management Journal, Vol. 37 No. 3, pp. 580-607.

Seibert, S.E., Crant, J.M. and Kraimer, M.L. (1999), "Proactive personality and career success”, Journal of Applied Psychology, Vol. 84 No. 3, pp. 416-427.

Sliter, M., Sliter, K. and Jex, S. (2012), "The employee as a punching bag: the effect of multiple sources of incivility on employee withdrawal behavior and sales performance", Journal of Organizational Behavior, Vol. 33 No. 1, pp. 121-139.

Spence Laschinger, H.K., Leiter, M., Day, A. and Gilin, D. (2009), "Workplace empowerment, incivility, and burnout: impact on staff nurse recruitment and retention outcomes", Journal of Nursing Management, Vol. 17 No. 3, pp. 302-311.

Ten Brummelhuis, L.L. and Bakker, A.B. (2012), "A resource perspective on the work-home interface: the work-home resources model”, American Psychologist, Vol. 67 No. 7, pp. 545-556.

Trougakos, J.P., Beal, D.J., Cheng, B.H., Hideg, I. and Zweig, D. (2015), “Too drained to help: a resource depletion perspective on daily interpersonal citizenship behaviors", Journal of Applied Psychology, Vol. 100 No. 1, pp. 227-236.

Van Dyne, L. and LePine, J.A. (1998), "Helping and voice extra-role behaviors: evidence of construct and predictive validity", Academy of Management Journal, Vol. 41 No. 1, pp. 108-119.

VandeWalle, D., Ganesan, S., Challagalla, G.N. and Brown, S.P. (2000), "An integrated model of feedback-seeking behavior: disposition, context, and cognition”, Journal of Applied Psychology, Vol. 85 No. 6, pp. 996-1003.

Vecchio, R. (2005), "Explorations in employee envy: feeling envious and feeling envied”, Cognition and Emotion, Vol. 19 No. 1, pp. 69-81.

Wu, X., Kwan, H.K., Wu, L.Z. and Ma, J. (2015), “The effect of workplace negative gossip on employee proactive behavior in China: the moderating role of traditionality", Journal of Business Ethics, Vol. 148 No. 4, pp. 801-815.

Yamada, D.C. (2000), "The phenomenon of workplace bullying and the need for status-blind hostile work environment protection", Georgetown Law Journal, Vol. 88, pp. 475-537.

Zhou, Z.E., Yan, Y., Che, X.X. and Meier, L.L. (2015), "Effect of workplace incivility on end-of-work negative affect: examining individual and organizational moderators in a daily diary study", Journal of Occupational Health Psychology, Vol. 20 No. 1, pp. 117-130.

\section{Further reading}

Porath, C.L. and Pearson, C.M. (2010), "The cost of bad behavior”, Organizational Dynamics, Vol. 39 No. 1, pp. 64-71.

Van Dyne, L. and Pierce, J.L. (2004), "Psychological ownership and feelings of possession: three field studies predicting employee attitudes and organizational citizenship behavior", Journal of Organizational Behavior, Vol. 25 No. 4, pp. 439-459.

\section{Corresponding author}

Yuhuan Xia can be contacted at: 16113159@bjtu.edu.cn

For instructions on how to order reprints of this article, please visit our website:

www.emeraldgrouppublishing.com/licensing/reprints.htm

Or contact us for further details: permissions@emeraldinsight.com 